\title{
Relationship Between Neurocognitive Profile and Cardiovascular Risk Factors
}

\author{
María de la P Scribano-Parada ${ }^{1,2 *}$, María del C Baez ${ }^{1}$, Ariel Balceda ${ }^{1}$, Mariana D Tarán ${ }^{1}$, Carla Buonanotte ${ }^{2}$, \\ Sergio Blencio ${ }^{1}$, Federico Buonanotte ${ }^{2}$ and Mónica Moya ${ }^{1}$ \\ ${ }^{1}$ Cátedra de Física Biomédica, Facultad de Ciencias Médicas, Universidad Nacional de Córdoba, Argentina \\ ${ }^{2}$ Cátedra y Servicio de Neurología, Hospital Nacional de Clínicas, Facultad de Ciencias Médicas, Universidad Nacional de Córdoba, Argentina
}

Submission: October 26, 2018; Published: January 16, 2019

*Corresponding author: María de la Paz Scribano Parada, Cátedra de Física Biomédica, Facultad de Ciencias Médicas, Universidad Nacional de Córdoba, Argentina. Santa Rosa 1085. Bo Alberdi. Córdoba, Córdoba, Argentina

Abstract

Introduction: Relationship between Cardiovascular Risk Factors (CVRF) and Neurocognitive Disorders (ND) is important, since the first are modifiable. It was studied the influence of cardiovascular risk factors in the neurocognitive profile.

Patients and Methods: Transversal analytic prospective study. Patients attended by cognitive symptoms were included. CVRF were recorded. According to Montreal Cognitive Assesment (MoCA) (cutoff of 26 points) two groups were made: Without cognitive disorder (NoCD) and cognitive disorder (CD). Cognitive Domains (CD) were evaluated. Risk groups were established (No CVRF, 1 CVRF, 2 CVRF, 3 or more CVRF). The relation between risk groups with invidual cd and with CD and noCD groups, was established. Chi Square for attributes. ANOVA and KruskalWallis for differences between groups, significance level $p<0.05$.

Results: 66 patients (female 57/86\%). Age 63.7 \pm 16 years. Most prevalent CVRF: physical inactivity, hypertension, smoking. MoCA average of 20.91 5.78. The CD group ( $\mathrm{n}=48$ ) received lower score in MoCA and worst performers in every cd. Groups 2 and 3CVRF able worst performance, and visuospatial/executive function were the most affected.

Conclusion: People over 65 years with increased cardiovascular risk, have poorer cognitive performance. The factors with the greatest implication would be female, age, years of schooling and summation of cardiovascular risk factors. The cd most affected are visuospatial and attention.

Keywords: Neurocognitive disorders; Cardiovascular risk factors; MoCA; Neurocognitive domains

Abbreviations: CVRF: Cardiovascular Risk Factors; ND: Neurocognitive Disorders; MoCA: Montreal Cognitive Assessment; CD: Cognitive Disorder; CD: Cognitive domains; NCD: Neurocognitive Disorders

\section{Introduction}

The advance of the medicine of last century has had its consequences to epidemiological level favoring to population aging. In this context it is that the neurocognitive disorders have acquired great importance [1,2]. The Neurocognitive Disorders (NCD) is a syndrome, which includes different entities. According to global statistics the dementia duplicates its frequency every 5 years from the 60 , coming to $30-40 \%$ in the major ones of 85 years old affecting more than 35 million persons in the whole world, being Alzheimer's Disease (EA) the most frequent reason followed by the NCD of vascular causes [1-3]. In Argentina the prevalence of dementia in general is estimated in $12.18 \%$ in subjects major of 65 años [4]. The NCD refers to a cognitive significant decline compared with the previous level of performance in one or more cognitive domains. The cognitive deficits must interfere with the Activities of Daily Living (ADL). It is necessary to reject a confusional syndrome and/or a mental disorder (for example: major depressive disorder, schizophrenia, etc.,) as reasons of the symptoms [1-3,5]. At present there are no effective treatments to confront the NCD. Because of that for the last years has been done special emphasis to its prevention. Inside the risk of factors mentioned for the development of the cognitive problems it finds hypertension (HBP) diabetes (DBT), dyslipidemia, smoking, sedentary lifestyle, low socioeconomic status, low educational level among others.

The recent finding of the relation between the cardiovascular risk factors (CVRF) and the NCD has provoked special interest since these are potentially modifiable factors. With the aim to recognize the relevancy of these factors population studies began in different parts of the world as United States [6-14], United Kingdom [15-18], Sweden [19], España [20,21] between others. Therefore, the purpose of the present work is to study the relationship between the neurocognitive profile and the cardiovascular risk factors in outpatients who consult for cognitive symptoms in our population. 
Specific objectives:

1. Describe the demographic variables: sex, age, level of education, marital status.

2. Detect the presence or absence of cognitive impairment from an appropriate test.

3. Analyze the differences in performance in the different neurocognitive domains (visuospatial/executive function, delay memory, language, identification, abstraction) in patients with and without cognitive impairment.

4. Establish the prevalence of CVRF (DBT, HBP, Dyslipemia, sedentary lifestyle, smoking) in the patients studied.

5. Define the relationship between performance in different neurocognitive domains and the presence of cardiovascular risk factors.

\section{Patients and Methods}

A prospective, descriptive cross - sectional study was carried out with patients who spontaneously attended the Clinical Neurology Service of the National Hospital of Clinics for 12 months from March 2014 to March 2015. We included all subjects who agreed to participate in the study voluntarily after being properly informed about it and signing a standard informed consent, approved by the hospital ethics committee. At all times the fundamental principles laid down in the Helsinki declaration were respected.

The information was collected in a form that included the personal and demographic data of each subject, the antecedents that could constitute a risk factor for the development of vascular cognitive impairment: hypertension, DBT, dyslipidemia, smoking, sedentary lifestyle [22]. The DBT was defined from the antecedent manifested by the patient or accompanying family member, or the use of oral antidiabetic drugs or insulin or both, or information recorded in the clinical history by competent professional [23-25].

The presence of hypertension was defined according to what was reported by family or patient, the use of antihypertensive medication, or diagnosis certified by a medical professional in the clinical history $[3,26]$.

Dyslipidemia was defined as cholesterolemia values greater than $200 \mathrm{mg} / \mathrm{dL}$, low density lipoprotein (less than $40 \mathrm{mg} / \mathrm{dL}$ in men or, less than $50 \mathrm{mg} / \mathrm{dL}$ in women) or triglycerides greater than $150 \mathrm{mg} / \mathrm{dL}$ or use of lipid-lowering drugs, or diagnosis supported by medical history $[2,23]$. Performing physical exercise in the previous year was assessed through the clinical interview defining as "sedentary" those individuals who performed less than 30 minutes daily of regular exercise and/or less than 3 days a week $[27,28]$. It was considered that the patient was smoker when the answer to the question: Do you smoke? was affirmative $[28,29]$. A neurological clinical examination was performed, which included a cognitive impairment test through the Montreal Cognitive Assesmen (MoCA), which has a maximum score of 30 points $[22,30]$. Based on the results of the application of this test, and taking into account a cut-off point of 26 points, the following groups were formed: Group A: Patients without cognitive impairment (NoDC); Group B: Patients with cognitive impairment (CD). In each group, individual scores were evaluated for each of the cognitive domains evaluated by the MoCA, which are: Visuospatial/executive function (0-5 points), Identification (0-3 points), Attention (0-6 points), Language (0-3 points), Abstraction (0-2 points), Deferred memory (0-5 points) and Temporospatial orientation ( $0-6$ points). In both groups, the relationship between the performance in the tests performed and the presence of the CVRF above mentioned was established.

\section{Statistical analysis}

The comparison between means was carried out using the Student test, for the quantitative data. The attributes variables will be analyzed by Chi square test. We used the ANOVA test and the Kruskal-Wallis test to find differences between the groups. The INFOSTAT 2014 program was used. A significance level of $p$ $<0.05$ was established. Results

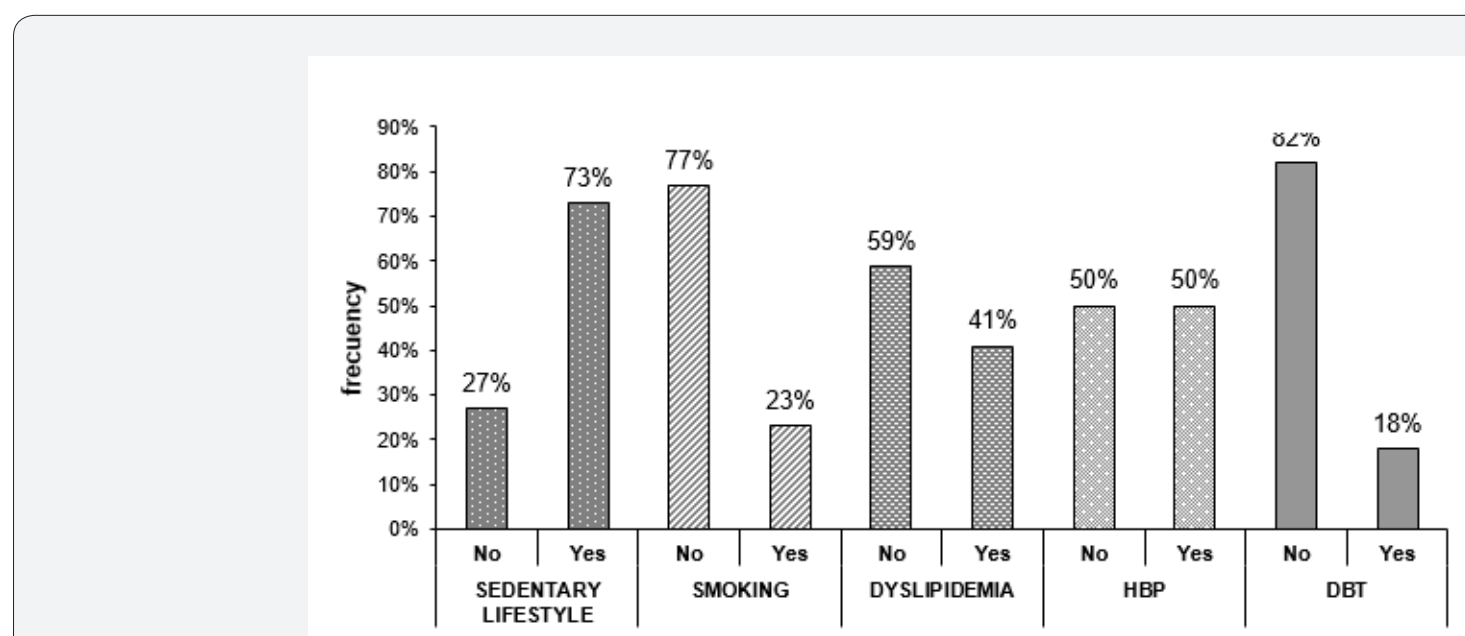

Figure 1: Bar Graphic where the prevalence of cardiovascular risk factors is shown in the patients studied $(n=68)$. 
Sixty-six patients were evaluated, predominantly female $(86 \%, n=57)$. The mean age was $63.69 \pm 15.91$. The mean of years of schooling was $8.65 \pm 5.25$. With a high percentage of patients with less than 12 years of schooling (73\%). Most of the patients were married $(55 \%, n=55)$, while $32 \%(n=21)$ were widowed and only $14 \%$ were single $(n=9)$.

Regarding the presence of cardiovascular risk factors (Figure 1), sedentary lifestyle $(73 \% ; n=48)$ and hypertension $(50 \% ; n=$ 33) were the most frequent in the group of study. DBT was the situation that obtained the lowest percentage $(18 \%, n=12)$.
Regarding the central tendency indices of MoCA test obtained by the patients studied, it can verify that the media score and the median for the same are close, standing at a value of 20.91 and 22 respectively. Patients studied express values between 8 and 30 points, being the maximum score for this test of 30 . Regarding the dispersion of the sign can say that the pointers oscillate between values of variance and the deviation is 32.90 and 5, 78 respectively. The data presented previously are reflected in Figure 2, which shows the distribution and function of the variable cognitive impairment measured by the MoCA test (Figure 2).
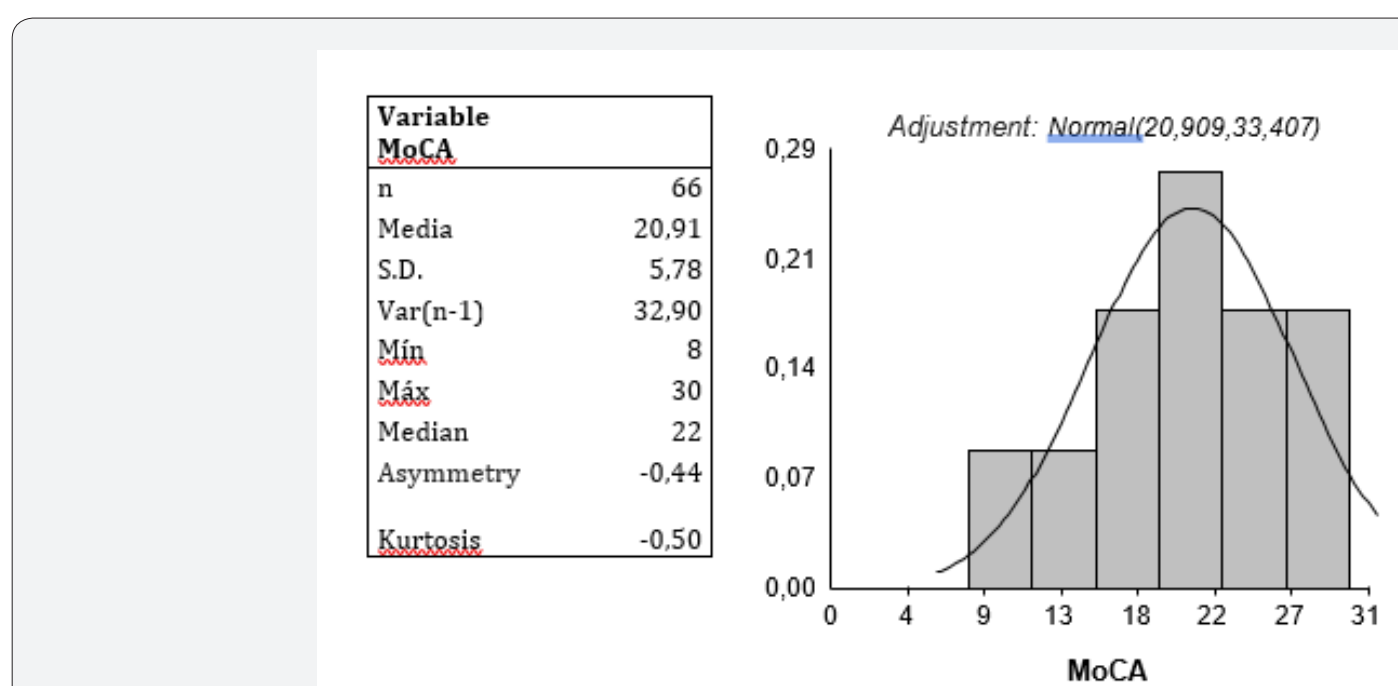

Figure 2: Histogram and normal fit curve obtained from the MoCA test in the patients studied $(n=66)$.

Table 1: Performance in the different cognitive domains of the patients according to the number of risk factors $(n=66)$.

\begin{tabular}{|c|c|c|c|c|c|}
\hline & No CVRF $\mathbf{n = 9}$ & $\mathbf{1}$ CVRF $\mathbf{n = 9}$ & $\mathbf{2}$ CVRF $\mathbf{n = 3 0}$ & $\mathbf{3} \mathbf{~}+\mathbf{C V R F} \mathbf{n = 1 8}$ & $\mathbf{p}$ \\
\hline Average age & $46,00 \pm 15,32$ & $61,33 \pm 23,44$ & $68,00 \pm 13,70$ & $66,50 \pm 15,32$ & 0,0298 \\
\hline Years of schooling & $11,33 \pm 6,00$ & $10,00 \pm 6,08$ & $8,13 \pm 4,16$ & $7,33 \pm 5,66$ & 0,2827 \\
\hline Female/n & $9 / 9$ & $6 / 9$ & $24 / 30$ & $18 / 18$ & 0,0409 \\
\hline Orientation & $5,00 \pm 1,50$ & $5,67 \pm 0,50$ & $5,20 \pm 1,42$ & $5,17 \pm 1,50$ & 0,9826 \\
\hline Deferred Recall & $2,33 \pm 1,80$ & $2,67 \pm 2,18$ & $2,20 \pm 1,92$ & $1,83 \pm 1,82$ & 0,7720 \\
\hline Identification & $2,33 \pm 1,00$ & $3,00 \pm 0,00$ & $2,80 \pm 0,41$ & $1,83 \pm 1,10$ & 0,0005 \\
\hline Attention & $4,00 \pm 2,29$ & $6,00 \pm 0,00$ & $4,50 \pm 1,31$ & $2,67 \pm 1,85$ & 0,0001 \\
\hline Abstraction & $1,33 \pm 0,50$ & $2,00 \pm 0,00$ & $1,70 \pm 0,65$ & $1,33 \pm 0,77$ & 0,0089 \\
\hline Language & $1,33 \pm 0,50$ & $1,33 \pm 1,32$ & $2,10 \pm 0,96$ & $1,33 \pm 0,67$ & 0,0201 \\
\hline
\end{tabular}

Taking the cut-off point of the test of 26 points, the patients were separated into two groups: Cognitive Impairment (CI) and no cognitive impairment (NoCI), forming the first group with those who obtained 25 points or less. The results could be seen in the Table 1 . The demographic factors that were associated with NCD were female (OR $=7.50, \mathrm{CI}=1.77$ - LS $=31.73, \mathrm{p}=0.0043)$, low educational level $(p=0.0002)$ and widowhood $(p=0.011)$. In the linear regression analysis, a decrease of 2,44 points in the MoCA test was observed for each less years of schooling $(p=0.0005)$. In the analysis of the cognitive domains evaluated by the MoCA test it can be seen that the CI group obtained lower scores in all the explored domains. However, the difference was not significant for the orientation domain Table 2.
When these values were compared with cardiovascular risk factors, it was observed that patients with 3 or more CVRF were the ones that obtained the lowest scores in all cognitive domains (Table 2). These differences between groups were significant for all domains except for orientation and delayed recall. Performance in the different cognitive domains is affected more by the sum of the risk factors than by the presence of one individual, since patients with a single risk factor obtained the highest scores in each individual domain than those without any risk factors (Table 2). Orientation and delayed recall did not seem to be affected the by the presence of cardiovascular risk factors and did not have significant results (Table 2). 
Table 2: Evaluation of performance in the different cognitive domains of the $\mathrm{Cl}$ and $\mathrm{NoCl}$ groups through the Kruskal-Wallis test. Scores are expressed as mean \pm SD.

\begin{tabular}{|c|c|c|c|}
\hline & NoCI $\mathbf{n = 1 8}$ & CI $\mathbf{n = 4 8}$ & $\mathbf{p}$ \\
\hline MoCA & $27,67 \pm 1,53^{*}$ & $18,38 \pm 4,62^{*}$ & 0,0001 \\
\hline Min & 26 & 8 & 0,0001 \\
\hline Max & 30 & 24 & 0,0001 \\
\hline VISUOESPACIAL & $4,67 \pm 0,49$ & $2,13 \pm 1,82$ & 0,0001 \\
\hline IDENTIFICATION & $3,00 \pm 0,00$ & $2,31 \pm 0,93$ & 0,0009 \\
\hline ATTENTION & $5,83 \pm 0,38$ & $3,50 \pm 1,79$ & 0,0001 \\
\hline LANGUAGE & $2,50 \pm 0,79$ & $1,38 \pm 0,94$ & 0,0001 \\
\hline ABSTRACTION & $2,00 \pm 0,00$ & $1,44 \pm 0,71$ & 0,0009 \\
\hline DEFERRED RECALL & $3,67 \pm 1,64$ & $1,63 \pm 1,67$ & 0,0001 \\
\hline ORIENTATION & $5,83 \pm 0,38$ & $5,00 \pm 1,52$ & 0,0592 \\
\hline
\end{tabular}

By associating the presence of risk factors with the overall performance in the test, a strong association between NCD and CVRF is observed as can be seen in Figure 3. The group with cognitive impairment presented 36 patients who presented 2 or
3 or more CVRF, whereas the group without cognitive impairment did not have patients with 3 or more CVRF. These differences were statistically significant $(\mathrm{p}=0.0028)$ (Figure 3$)$.

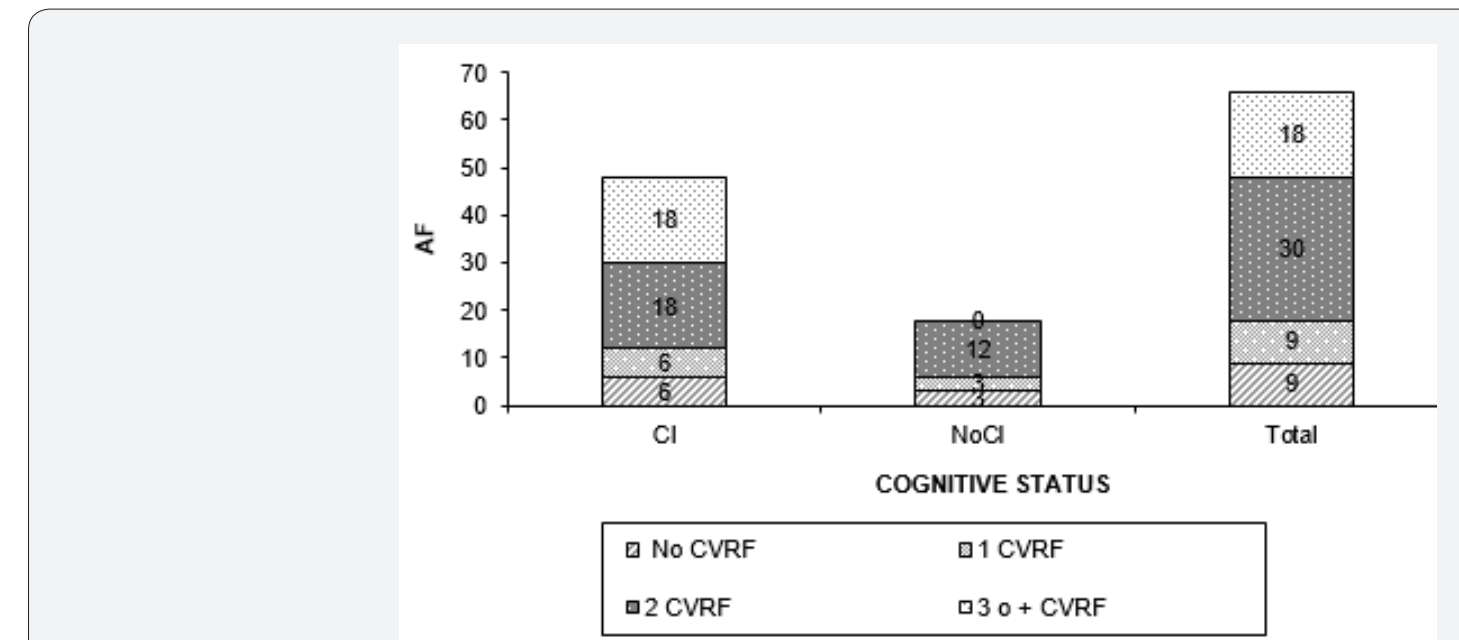

Figure 3: Stacked bar graph where the composition by groups of the presence of CVRF is observed. Differences were significant in all groups $(p=0.0230)$.

\section{Discussion}

According to the results obtained, patients older than 65 years with a history of cardiovascular disease are related to a lower cognitive performance when there are no clinical manifestations of cerebrovascular disease. The factors that would have the mayor imply would be sex, age, years of schooling and the sum of CVRF. The most affected cognitive domains are visuospatial functions and attention, while orientation does not appear to be influenced by any of the factors aforementioned. The patients evaluated in this study had similar age averages and gender distribution as the observations in other studies [1-4,26,31]. The relationship of these factors to the NCD was maintained according to the literature: age, low educational level, widowhood and female sex, predispose to the development of NCD [6,24,29]. Regarding the prevalence of CVRF, DBT was not frequently presented in contrast to what was observed in other studies, whereas hypertension was present in half of the patients studied. However, research has also found that CVRF, especially HBP and DBT, already have effects on cognition in adults of that age range [1,3,26,15,32-34]. The high prevalence of sedentary lifestyle coincides with the latest records on chronic non-communicable diseases in Argentina where it was detected that up to $75 \%$ of the population did not practice any physical activity in the regular way or in the inadequate way [35].

In the sample studied only $23 \%$ of the patients were active smokers but the figures for the population in Argentina provide higher data. Chronic exposure to tobacco causes atherosclerosis and subsequent hypertension. The relationship between smoking and negative changes in the Mini-Mental State Examination (MMSE) was evaluated in the European Community Concerted Action Epidemiology of Dementia (Eurodem) study, and a significant decrease in MMSE was found in subjects who smoked against non-smokers. This is why it is currently recognized as a risk factor for cognitive impairment [23,29,36]. Dyslipemia was present in $41 \%$ of the patients studied, and although it was not part of the formal registry, most of the patients did not receive adequate treatment or complete with an appropriate diet. 
hypercholesterolemia increases the formation of amyloid beta, increasing the formation of the amyloid precursor protein. In addition, it favors the conversion of fibrillar amyloid beta to the formation of neuritic plaques, for that reason the importance of its control $[1,2,26]$. Regarding the cognitive performance of the patients, $72 \%(n=48)$ presented poor performance in the applied test. The patients studied in the CI group had lower scores in all cognitive domains compared to the control group. The domains of visuospatial/executive function and language were the most severely affected, while in orientation they obtained very similar scores and the differences were not significant. By contrasting the performance in the different domains in the different risk groups we see that the scores do not follow the expected pattern, and that the group with a single risk factor scored higher than the group without risk factors.

This is probably due to the fact that these groups were very homogeneous in terms of years of schooling (No CVRF: $11.33 \pm$ $6.03,1$ CVRF $10.00 \pm 6.00$ ), and sex. But a more in-depth analysis specifically assessing which risk factor is involved would have been enriching at this point. However, the study design that valued these as categorical variables does not allow this type of analysis to obtain values with the necessary precision. In a Spanish study the comparison between the low, mild and moderate risk groups indicated that the moderate risk group was the only one that showed cognitive differences, similarly to what occurred with group $1 \mathrm{CVRF}$ in the present study. In this study, performance in visuoconstructive functions in moderate risk group was significantly lower with respect to the low risk group. As in our study for group $1 \mathrm{CVRF}$, a small number of patients were also observed for the moderate risk group $(n=10)$ [32].

However, for the groups with 2 or 3 or more risk factors the difference was clear, they showed low performance in all domains, low level of schooling and means of age higher than the other groups which would demonstrate that the effect of the CVRF would seem to be more sensitive to the sum of these. Finally, when assessing the global cognitive function and contrasting the NoCD and CD groups with the different risk groups, it is observed that the CD group is composed mainly of patients with more risk factors, and the relationship of these was significant in the same way observed in different population studies. In our country, studies that systematically investigate the relationship between NCD and CVRF have not yet been performed. In Spain, a small study was carried out on 90 people, in which cardiovascular risk was assessed through the REGICOR scale (validated Framingham score for the Spanish population) and cognitive redemption. This study showed that at a higher cardiovascular risk, the most affected functions were visuoconstructive and psychomotor speed/coordination similar to what occurred in the sample [32,33]. In the Framingham cohort study the alterations were also seen in visuospatial memory, organization and tracking, attention, concentration and abstract reasoning. In ELSA (English Longitudinal Study of Aging) study carried out in the United Kingdom, however, they do not coincide with the results of the previous studies nor with the present work since it refers alterations in verbal memory, semantic verbal fluency, processing speed and general cognitive functioning this may be due to differences in the composition characteristics of the samples in terms of age, sex, and sample size, which could modify cardiovascular risk patterns $[32,33,37,38]$. In Framingham and ELSA studies, participants were 50 years or older. In addition, these studies did not exclude people with mild cognitive impairment, which may have overestimated cognitive impairment.

However, it is common in most studies that visuomotor function is most affected. This is the ability most closely related to the integrity of the cerebral white matter. Cerebral white matter is particularly susceptible to cerebral hypoperfusion. Probably, the negative effect of CVRF on the integrity of the cerebral white matter would be the pathophysiological mechanism involved. In the DBT microvascular involvement, the proinflammatory state leading to endothelial dysfunction and the presence of oxidative stress and alterations in the metabolism of amyloid beta and tau protein would be the mechanism that would bind the presence of NCD $[1,2,23,24,32,33]$. While in the hypertensive patients the increase of the atherosclerotic load alters the cerebral flow which accelerates the degeneration due to an inefficient metabolism. The lesions occur mainly in the white matter in neocortex and hippocampus. This has been associated with hippocampal and tonsillar atrophy predisposing to the development of NCD type Alzheimer's disease $[32,37,38]$. A follow-up of the cognitive state with larger sample size would allow us to evaluate if this group of patients produces a higher incidence of cognitive impairment and dementia in the medium and long term, when comparing different risk groups and other variables [39-42]. This work supports the current recommendations that emphasize that adequate prevention in low-risk cardiovascular groups would decrease the incidence not only of cardiovascular events but also of NCD.

\section{Acknowledgements}

The present study was funded by sub-grant from the Science and Technology Secretariat of the Faculty of Medical Sciences, National University of Cordoba, Argentina.

\section{References}

1. Hughes T, Ganguli M (2010) Factores de riesgo de demencia en la vejez modificables en las etapas medias de la vida. Rev Neurol 51(5): 259262.

2. Rodriguez Poncelas A (2007) Factores de riesgo cardiovascular y deterioro cognitivo. Alzheimer. Real Invest Demenc 35: 30-37.

3. Reig Puig L, Antón Rodrigo I y Sánchez Ferrín P (2011) Relación entre hipertensión arterial y la demencia. Hipertens riesgo vasc 28(5-6): 182-195.

4. Melcon CM, Bartoloni L, Katza M, Del Mónaco R, Mangone CA, et al. (2010) Propuesta de un Registro Centralizado de Casos con Deterioro Cognitivo en Argentina (ReDeCAr) basado en el Sistema Nacional de Vigilancia Epidemiológica. Neurol Arg 2(3): 161-166.

5. American Psychiatric Association (2014) DSM-5. Manual diagnóstico y estadístico de los trastornos mentales. Editorial Médica Panamericana. 
6. Fillenbaum GG, van Belle G, Morris JC, Mohs RC, Mirra SS, et al. (2008) CERAD (Consortium to Establish a Registry for Alzheimer's Disease) The first 20 years. Alzheimers Dement 4(2): 96-109.

7. Heyman A, Fillenbaum G, Nash F (ed). (1997) Consortium to Establish a Registry for Alzheimer's Disease: The CERAD experience. Neurology 49(3): 13

8. University of Pittsburgh Alzheimer's Disease Patient Registry, Pennsylvania.

9. University of Washington Alzheimer's Disease Patient Registry (ADPR), USA.

10. Larson EB, Kukull WA, Teri L, McCormick W, Pfanschmidt M, et al (1990) University of Washington Alzheimer's Disease Patient Registry (ADPR): 1987-1988. Aging (Milán) 2: 404-408.

11. Alzheimer's Disease and Other Dementias (2015) The New York State Dementias Registry, USA.

12. Arnold School of Public Health South (2015). Alzheimer's disease Registry. USC, University of South Carolina.

13. Still CN, Jackson KL, Brandes DA, Abramson RK, Macera CA (1990) Distribution of major dementias by race and sex in South Carolina. J S C Med Assoc 86(8): 453-456.

14. West Virginia Alzheimer's disease Registry (2015)

15. Holmes C (1996) The Camberwell Dementia Case Register. Int J Geriatr Psychiat 11(4): 369-375.

16. Roosa LL, Nicola JP (1999) A Research Registry: Uses, Development, and Accuracy. J Clin Epidemiol 52(1): 39-47.

17. Iliffe S, Curry L, Kharicha K, Rait G, Wilcock J, et al. (2011) Developing a Dementia Research Registry: a descriptive case study from North Thames DeNDRoN and the EVIDEM programme. BMC Med Res Methodol 11(1): 9.

18. Scottish Dementia Research Interest Register (2015).

19. Swedish Dementia Registry, SveDem (2015).

20. Garre Olmo J, Flaque M, Gich J, Pulido TO, Turbau J, et al. (2009) A clinical registry of dementia based on the principle of epidemiological surveillance. BMC Neurol 9: 5.

21. Garre Olmo J, López Pousa S, Monserrat Vila S, Pericot Nierga I, Turon Estrada A (2007) The feasibility of a registry of dementias: clinical features and diagnostic coverage. Rev Neurol 44(7): 385-391.

22. Malek Ahmadi M, Davis K, Belden CM, Sabbagh MN (2014) Comparative Analysis of the Alzheimer's Questionnaire (AQ) with the CDR Sum of Boxes, MoCA, and MMSE. Alzheimer Dis Assoc Disord 28(3): 296-298.

23. Roberts RO, Knopman DS, Geda YE, Cha RH, Pankratz VS, et al. (2014) Association of diabetes with amnestic and nonamnestic mild cognitive impairment. Alzheimer's Dement 10(1): 18-26.

24. Canazaro de Mello D, Fernandes Lopes RM, Lopes do Nascimento RF, Cunha Sartori F, de Lima Argimon II (2010) El Deterioro Cognitivo en Pacientes Ancianos con Diabetes Mellitus Tipo 2 y la Identificación de Formas de Prevención. Revista Neuropsicología, Neuropsiquiatría y Neurociencias10(2): 29-42.

25. Mejía-Arango S, Zúñiga-Gil C (2011) Diabetes Mellitus como factor de riesgo en la población adulta mexicana. Rev Neurol 53(7): 397-405.

26. De Cerchio AE, Parras J, Reyes LM, Vicario A (2015) Deterioro cognitivo y rigidez arterial. Rev Fed Arg Cardiol 44(Supl 1 HTA): 28-32.
27. Lojo Seoane C, Facala D, Juncos Rabadán O (2012) ¿ Previene la actividad intelectual el deterioro cognitivo? Relaciones entre reserva cognitiva y deterioro cognitivo. Rev Esp Geriatr Gerontol 47(6): 270278.

28. Neeper SA, Gomez-Pinilla F, Choi J, Cotman CW (1996) Physical activity increases MRNA for brain-derived neurotrophic factor and nerve growth factor in rat brain. Brain Res 726(1-2): 49-56.

29. Gomez Viera N, Bonnin Rodríguez BM, Gómez de Molina Iglesias MT, Fernández BY, González ZA (2003) Characterización clínica de pacientes con deterioro cognitivo. Rev cubana med [Serie online] enemar 42(1): 5p.

30. Alagiakrishnan K, Zhao N, Mereu L, Senior P, Senthilselvan A (2013) Montreal Cognitive Assessment Is Superior to Standardized MiniMental Status Exam in Detecting Mild Cognitive Impairment in the Middle-Aged and Elderly Patients with Type 2 Diabetes Mellitus. Biomed Res Int 5 p.

31. Terraza P (2015) Deterioro Cognitivo Vascular. Rev Arg Alz y otros trastornos cognitivos 23: 25-30.

32. Miralbell J, Sorianoa JJ, López Canciob E, Arenillasc JF, Doradob L, et al. (2010) Factores de riesgo vascular y rendimiento cognitivo en personas de 50 a 65 años. Neurol Arg 25(7): 422-429.

33. Lorius N, Locascio JJ, Rentz DM, Johnson KA, Sperling RA, et al.; for the Alzheimer's Disease Neuroimaging Initiative (2015). Vascular disease and risk factors are associated with cognitive decline in the Alzheimer's disease spectrum. Alzheimer Dis Assoc Disord 29(1): 18-25.

34. Lopez Perez-Diaz AG, Jimenez-Jaimez J (2011) La hipertensión arterial como factor de riesgo para el deterioro cognitivo en la vejez: estudio de revision. Psicogeriatria 3(1): 19-28.

35. Argentina en Movimiento. Hábitos deportivos de la población argentina. Investigación realizada por la Secretaría de Turismo y Deporte de la Nación, con el soporte calificado del Instituto Nacional de Estadística y Censos (INDEC) 2000.

36. Aguilar Navarro SG, Reyes Guerrero J, Borgues G (2007) Cognitive impairment and alcohol and cigarette consumption in Mexican adults older than 65 years. Salud pública Méx 49(Suppl 4): S467-S474.

37. Llewellyn DJ, Lang IA, Xie J, Huppert FA, Melzer D, et al. (2008) Framingham stroke risk profile and poor cognitive function: A population-based study. BMC Neurol 8: 12.

38. Elias MF, Sullivan LM, D’Agostino RB, Elias PK, Beiser A, et al. (2004) Framingham stroke risk profile and lowered cognitive performance. Stroke 35(2): 404-409.

39. Belfort-Deaguiar R, Constable RT, Sherwin RS (2014) Functional MRI Signal Fluctuations: A Preclinical Biomarker for Cognitive Impairment in Type 2 Diabetes?. Diabetes 63(2): 396-398.

40. Cooper B, Holmes C (1997) The Camberwell Dementia Case Register: a valuable research tool. IPA Bulletin 14: 23-24.

41. Llibre Guerra JC, Guerra Hernández MA, Perera Miniet E (2008) Comportamiento de las enfermedades crónicas no transmisibles en adultos mayores. Rev Cubana Med Gen Integr Dic 24(4): aprox. 4 p.

42. Barengo Noël C, Tuomilehto Jaakko O, Nissinen A, Puska P (2011) Estrategias de comunicación en la mejora de los factores de riesgo cardiovascular y enfermedades cardiovasculares en el Proyecto Karelia del Norte. Revista de Comunicación y Salud. 1(1): 42-51. 
(CC) This work is licensed under Creative BY DOI: $10.19080 /$ JOCCT.2019.12.555848

\section{Your next submission with Juniper Publishers} will reach you the below assets

- Quality Editorial service

- Swift Peer Review

- Reprints availability

- E-prints Service

- Manuscript Podcast for convenient understanding

- Global attainment for your research

- Manuscript accessibility in different formats

( Pdf, E-pub, Full Text, Audio)

- Unceasing customer service

Track the below URL for one-step submission https://juniperpublishers.com/online-submission.php 